\title{
Evidence for Alteration in Chemical and Physical Properties of Water and Modulation of its Biological Functions by Sunlight Transmitted through Color Ranges of the Visible Spectrum-A Novel Study
}

\author{
Hari H. P. Cohly ${ }^{*}$, Asit Panja ${ }^{2}$, William L. Reno III ${ }^{1}$, Don Obenhuber ${ }^{3}$, Margot S. Koelle ${ }^{4}$, Suman K. Das ${ }^{1}$, Michael \\ F. Angel ${ }^{1}$, and M. Rajeswara Rao ${ }^{5}$ \\ ${ }^{1}$ Department of Surgery, University of Mississippi Medical Center, 2500 North State Street, Jackson, Mississippi, 39216-4505, USA \\ ${ }^{2}$ Division of Gastroenterology, Department of Medicine, UMDJ-NJ Robert Wood Johnson Medical School, New \\ Brunswick, NJ 08903, USA \\ ${ }^{3}$ Materials and Processes Laboratory, NASA-Marshall Flight Space Center, Huntsville, Alabama, 35812, USA \\ ${ }^{4}$ State University of New York at Buffalo, Department of Microbiology, Buffalo, New York, 14214-3000, USA \\ ${ }^{5}$ Department of Zoology, Sri Venkateswara University, Tirupati, 517 502, India \\ * Correspondence to Dr. Hari H. P. Cohly. Email: hcohly2004@yahoo.com
}

Received: 10 January 2005 / Accepted: 10 April 2005 / Published: 14 August 2005

\begin{abstract}
We investigated the changes in the properties of water when exposed to sunlight for 40 days. We hypothesize and prove that solar irradiation to water entraps electromagnetic radiation as potential energy, which becomes kinetic energy in various systems. It is postulated that photochemically-induced energy transfers, associated with individual spectral emission of visible spectrum of solar light, exert diverse influences on biological systems. Bottles of distilled water, individually wrapped in spectral-colored cellophane were exposed to sunlight and compared to an unwrapped bottle to determine chemical and physical changes as well as modifications of biological properties. Each bottle of water was named according to the color of cellophane paper with letter E (stands for exposed) as a prefix with (E-violet, E-indigo, E-blue, E-green, E-yellow, E-orange, and Ered). E-control (without wrap) was exposed to polychromatic sunlight. This study addresses two main issues viz., the chemical and physical changes in E-water and its effect on biological activities. Chemical and physical composition analysis using inductively coupled plasma atomic emission spectrometry; physical conductance by a Wheatstone Bridge type conductivity meter; osmolarity by a vapor pressure osmometer; and, salt solubility profile of $10 \%$ sodium bicarbonate were determined. Furthermore, testing the effect of E-waters on human lymphocyte proliferation, mosquito larvae hatching and seed germination determined the functional role of solar radiation through specific spectrum/s of visible light on various biological processes. We found that water exposed to visible spectral emissions of sunlight had an altered elemental composition, electrical conductance, osmolarity and salt-solubility, as well as differences in bio-modulatory effects. A gradual increase in leaching of Boron from Eviolet to E-red was noted. E-indigo showed maximal increase in electrical conductance and maximal salt solubility of sodium bicarbonate. E-blue inhibited phyto-hemagglutinin-induced immune cell proliferation and mosquito larvae hatching. E-orange stimulated root elongation in seed germination. We conclude that 40-day exposure of water to specific solar spectrum changes chemical and physical properties and influences on biological activity.
\end{abstract}

Keywords: boron, conductance, germination, mosquito larva hatching, osmolarity, salt solubility, solar energy, T cell proliferation, water.

\section{Introduction}

Water is an essential constituent of all living organisms, and sunlight is our main source of energy [1]. There is an absolute necessity in daily life for water, especially uncontaminated water. In order to keep water free from life-threatening contaminants, an elaborate purification system is in place in western countries that is not found feasible in some Third-World countries where the water sources usually have fecal contaminants. Exposure of contaminated water to sunlight can be sterilizing [2-5]. The process is dependent upon the composition of the vessel, as well as intensity and time of exposure [2]. Placing bottled (plastic/glass) water in 
sunlight for a minimum of $5 \mathrm{hrs}$ and up to a maximum of $48 \mathrm{hrs}$ has been scientifically shown to detoxify and decontaminate water infected with bacteria and viruses [3-5]. Extended times of exposure to sunlight for approximately six weeks, has been used for solarization of soil [6].

Water alone has also shown potential for healing. Healing with water containing various additives as calcium chloride, magnesium sulfate, sodium metasilicate and sulfated castor oil has been patented by Willard [7]. In ancient times, water, after exposure to direct sunlight and filtered through colored glass, was used as a therapeutic modality [8]. The action of sunlight on bottled water, as used in the sterilization study, had been reported as irreversible and documented by the inability of coliforms to re-grow after placing the exposed bottled water in the dark storage [4]. However, biomodulatory and physico-chemical effects of individual spectrums of visible light on water have not been characterized.

It is our hypothesis that solar irradiation to water entraps electromagnetic radiation as potential energy which becomes kinetic energy in various systems. The central hypothesis tested in this paper assumed that photochemically-induced energy transfers, associated with individual spectral emission of visible spectrum of solar light, exert diverse influences on biological systems. To test this hypothesis, sterile water in unopened capped plastic bottles (which allows 50\% light transmission as per the information provided by the manufacturer) was used. Dye-impregnated cellophane paper covering clear glass or translucent $(50 \%)$ plastic was used as an absorption filter to selectively allow exposure of semi-monochromatic light to water in these bottles. The cellophane wrapped bottles were exposed to sunlight through violet, indigo, blue, green, yellow, orange, and red colored cellophane paper in an open environment in an upright position. Each of the exposed (E) water was named according to the color of the cellophane paper, e.g., E-violet, E-indigo, E-blue, Egreen, E-yellow, E-orange, E-red (Figure 1). E-control was exposed to polychromatic sunlight. Thus, the sun provides the heat in the daytime while in the absence of sun lower temperatures occur during nighttime. In essence, this provides a constant cycle of evaporation and condensation in the enclosed plastic bottle. Further, water when irradiated by the sun is exposed to decreasing amounts of energy of radiation; violet being high frequency of light energy whereas red is of lower frequency and higher heat index. After the exposure of 40 days, the bottled water was wrapped with aluminum foil to protect from exogenous irradiation.

The overall aim of this study is to scientifically investigate the changes in the properties of water when exposed to sunlight for 40 days. This study specifically addresses the chemical and physical changes in exposed (E) water, and its effect on biological activity. The potential biological significance of changes in the Ewaters was determined by testing their effect on: 1) lymphocyte (human peripheral blood) proliferation, 2) mosquito larva (Anopheles) viability and 3) seed (Diolichos Uniflorous) germination.



Figure1: Diagrammatic representation of the Chemical, Physical and Biological modifications in properties investigated

\section{Methods}

\section{Preparation of Water}

Sterilized distilled water in sterile translucent $(50 \%$ transparent) plastic (a co-polymer of $98 \%$ polypropylene and $2 \%$ polyethylene) bottles was obtained from Baxter (Deerfield, Illinois). Double-distilled water was obtained from the laboratory, and well water was obtained from a well in Columbus, Texas. The doubledistilled water was placed in sterile 500-ml clear glass media bottles. Each of the glass bottles was then heatsterilized in an autoclave at $121^{\circ} \mathrm{C}$ for 15 minutes, and wrapped in cellophane of a different color. Well water was used to fill cleaned 16-ounce clear glass sterilized bottles, and heat sterilized. Bottles were cellophanewrapped corresponding to the visible individual spectral colors of violet, indigo, blue, green, yellow, orange, and red. The colored cellophane color distribution in the red $(600-700 \mathrm{~nm})$, green $(500-600 \mathrm{~nm})$ and blue $(400-500 \mathrm{~nm})$ filter was measured on TQC90, a color transmission and reflection densitometer, Electronic Systems Engineering Company, Inc. (Cushing, OK). Violet wrap had 38\% transmission $(\mathrm{T})$ in the red filter, $12 \% \mathrm{~T}$ in the green filter and 55\% $\mathrm{T}$ in the blue filter. Similarly indigo wrap had $4 \% \mathrm{~T}$ in red filter, $54 \% \mathrm{~T}$ in green and $79 \% \mathrm{~T}$ in blue; blue wrap had $27 \% \mathrm{~T}$ in red filter, $41 \% \mathrm{~T}$ in green filter and $52 \% \mathrm{~T}$ in blue filter; green wrap had $6 \% \mathrm{~T}$ in red filter, $50 \% \mathrm{~T}$ in green filter and $10 \% \mathrm{~T}$ in blue filter; yellow wrap had $49 \% \mathrm{~T}$ in red filter, $44 \% \mathrm{~T}$ in green filter and $13 \% \mathrm{~T}$ in blue filter; orange wrap had $83 \% \mathrm{~T}$ in red filter, 54\% $\mathrm{T}$ in green filter and 3\% $\mathrm{T}$ in blue filter; red wrap had $74 \% \mathrm{~T}$ in red filter, $0 \%$ transmission in green filter and $4 \%$ transmission in blue filter. Controls included one unwrapped bottle of each type of water; i.e., well water and double-distilled. The distilled water and well-water were exposed to sunlight from July through August in Columbus, Texas. The doubledistilled water in plastic bottles was exposed to sunlight from October through November in Jackson, Mississippi. Bottles (minimum of two bottles for each cellophane paper) were exposed to sunlight for 40 days and thereafter the bottles were placed in the dark to avoid unwanted light exposure without removal of 
cellophane. All experiments used water obtained from plastic bottles except for studies in germination.

\section{Chemical Composition and Salt Solubility}

For chemical composition analysis, eight E-water samples were placed in 15-ml sterile tubes wrapped with aluminum foil to protect them from further exposure to radiation. These samples were sent to NASA-Marshall Space Flight Center, Huntsville, AL for analysis using inductively coupled plasma atomic emission spectrometry (ICP) [9].

Salt solubility of $10 \%$ sodium bicarbonate was evaluated in each of the eight E-waters. Eight $15 \mathrm{ml}$ sterile polystyrene tissue culture tubes were filled with 1 gram of sodium bicarbonate and $10 \mathrm{ml}$ of the different Ewaters at room temperature. The tubes were vortexed to dissolve the solute. After 24 hours, solubilization was determined macroscopically.

\section{Physical Conductance and Osmolarity}

Physical conductance of each E-water was measured using a Wheatstone Bridge type conductivity meter. Osmolarity of E-waters was determined using the Wescor 5100 vapor pressure osmometer, Wescor, Inc. (Logan, UT).

\section{T cell Prolifération}

Lymphocytes were incubated with phytohemagglutinin (P), a T cell mitogen, in presence or absence of E-waters. In a cell proliferation assay [10], peripheral blood $(10 \mathrm{ml})$ was obtained from healthy subjects and lymphocytes were purified using ficol-hypaque gradient. Lymphocytes were removed, washed and resuspended in RPMI 1640 containing 1\%penicillin, 1\%streptomycin and $10 \%$ fetal bovine serum using standard laboratory procedures. A mixture of $2 \times 10^{5}$ cells in $100 \mu 1$ was plated into each well of a flat-bottom 96-well plate and incubated both with media alone and media supplemented with phytohemagglutinin at 10ng per $\mathrm{ml}$. Ninety $\mu \mathrm{l}$ of E-water group was plated into their respective wells in triplicate. Ten $\mu \mathrm{l}$ of $10 \mathrm{x}$ phosphate buffered saline (PBS) was placed in each well to make the solution isotonic. The samples were incubated for 3 days at $37^{\circ} \mathrm{C}$, pulsed with $1 \mu \mathrm{Ci}$ of tritiated thymidine, harvested after 18 hours onto filter paper, and radioactivity was determined in a beta counter.

\section{Mosquito Larva Viability}

Mosquito larvae, particularly the IV-in stared stages of the Anopheles species, were removed from an outdoor stagnate water supply and ten larvae were placed in 12well plates for viability testing. These ten mosquito larvae were mixed with $500 \mu \mathrm{l}$ of pond water plus $500 \mu \mathrm{l}$ of E-water covering the full spectrum of light. The Ewaters were diluted 1:10 and 1:100 where the dilutions were made with unexposed distilled water (Baxter, Deerfield, IL). The plates were incubated for 10 days (normal hatching time for mosquito larvae) at room temperature for normal morphogenesis to take place and the viability was determined at 24, 48, 72, 96 and 240 hours. A mosquito was considered viable if the wings had emerged. The experiments were performed twice in triplicate. Data shown in the Table 2 were observations from $\mathrm{t}=24 \mathrm{hrs}, 48 \mathrm{hrs}, 72 \mathrm{hrs}, 96 \mathrm{hrs}$. The experiment was carried out for 10 days $(240 \mathrm{hrs})$, however, no difference was noted between 96 and 240 hrs (data not shown). Three conditions were tested for each time period, i.e., the mosquito larvae were incubated with undiluted E-water plus two dilutions of E-water at 1:10 and $1: 100$.

\section{Seed Germination}

Eight petri dishes were filled with 7 grams of Horsegram (Dolichos Uniflorous) seeds [11]. Each petri dish with a $4 \times 4 \mathrm{~cm}$ cotton gauze was filled with a different E-water $(25 \mathrm{ml})$, and the seeds were allowed to incubate at room temperature for up to 48 hours. In this experimental design, the effects of energy on the material of the container (transparent versus translucent), season of incubation (summer versus fall), and the type of water (well water versus distilled water) were tested. Three types of water were tested viz., a) distilled water in plastic bottles (DWPB; fall), and b) well water in glass bottles (WWGB; summer) and c) distilled water in glass bottles (DWGB; summer). The cotyledons of the seeds were measured (in millimeters) from their point of visible emersion. The seeds were then incubated for an additional 24 hours and measured again. Three separate experiments were performed in duplicate, one using well water, one using sterilized double-distilled water in sterilized transparent glass bottles, and one using sterilized distilled water in sterilized translucent plastic bottles (Commercially available from Baxter).

\section{Statistical Analysis}

Statistical analysis was performed by one-way ANOVA for multiple samples by multiple comparison (turkey test) or by Student's-t-testing with matched pairing if appropriate, as well as regression analysis.

\section{Results}

First, the chemical analysis was performed on 72 elements (Table 1A) of which only boron, calcium, magnesium and rubidium showed coefficient of variances $(\mathrm{CV})$ greater than 10 when compared to $\mathrm{E}$ control (Table 1B). In particular, boron concentration in parts per billion (ppb) steadily increases from E-Violet water $(13,137 \mathrm{ppb})$ to E-Red water $(27,563 \mathrm{ppb})$, while E-control corresponded to $12,536 \mathrm{ppb}$. The compositional distribution of Boron according to the photon energy in electron volts $(\mathrm{eV})$ has been depicted in Figure 2. The Binomial equation for the compositional distribution of boron which gives the best fit is:

$$
\begin{aligned}
& y=9 E-09 x^{2}-0.0005 x+7.4297 \text {, with an } \\
& R^{2}=0.9793 \text {, where } \\
& y=\text { photon energy in electron volts }(e V) \text {, and } \\
& x \text { is the atomic mass (ppb). }
\end{aligned}
$$


Table 1A: List of 72 elements analysed by Inductively Couple Plasma Spectroscopy.

\begin{tabular}{ccccccccc}
\hline $\mathrm{Ag}$ & $\mathrm{Al}$ & $\mathrm{As}$ & $\mathrm{Au}$ & $\mathrm{B}$ & $\mathrm{Ba}$ & $\mathrm{Be}$ & $\mathrm{Bi}$ & $\mathrm{C}$ \\
$\mathrm{Ca}$ & $\mathrm{Cd}$ & $\mathrm{Ce}$ & $\mathrm{Co}$ & $\mathrm{Cr}$ & $\mathrm{Cs}$ & $\mathrm{Cu}$ & $\mathrm{Dy}$ & $\mathrm{Er}$ \\
$\mathrm{Eu}$ & $\mathrm{Fe}$ & $\mathrm{Ga}$ & $\mathrm{Gd}$ & $\mathrm{Ge}$ & $\mathrm{Hf}$ & $\mathrm{Hg}$ & $\mathrm{Ho}$ & $\mathrm{I}$ \\
$\mathrm{In}$ & $\mathrm{Ir}$ & $\mathrm{K}$ & $\mathrm{La}$ & $\mathrm{Li}$ & $\mathrm{Lu}$ & $\mathrm{Mg}$ & $\mathrm{Mn}$ & $\mathrm{Mo}$ \\
$\mathrm{N}$ & $\mathrm{Na}$ & $\mathrm{Nb}$ & $\mathrm{Nd}$ & $\mathrm{Ni}$ & $\mathrm{Os}$ & $\mathrm{P}$ & $\mathrm{Pb}$ & $\mathrm{Pd}$ \\
$\mathrm{Pr}$ & $\mathrm{Pt}$ & $\mathrm{Rb}$ & $\mathrm{Re}$ & $\mathrm{Rh}$ & $\mathrm{Ru}$ & $\mathrm{S}$ & $\mathrm{Sb}$ & $\mathrm{Sc}$ \\
$\mathrm{Se}$ & $\mathrm{Si}$ & $\mathrm{Sm}$ & $\mathrm{Sn}$ & $\mathrm{Sr}$ & $\mathrm{Ta}$ & $\mathrm{Tb}$ & $\mathrm{Te}$ & $\mathrm{Th}$ \\
$\mathrm{Ti}$ & $\mathrm{Tl}$ & $\mathrm{Tm}$ & $\mathrm{V}$ & $\mathrm{W}$ & $\mathrm{Y}$ & $\mathrm{Yb}$ & $\mathrm{Zn}$ & $\mathrm{Zr}$ \\
\hline
\end{tabular}

Table 1B: Variation of elements contained in spectral irradiated distilled water as measured by Inductively Couple Plasma Spectroscopy (PPB).

\begin{tabular}{|c|c|c|c|c|c|c|c|c|c|}
\hline$E l$ & $\begin{array}{c}\text { Control, } \\
\text { Polychromatic }\end{array}$ & $\begin{array}{c}\text { Violet } 400 \mathrm{~nm} \\
\quad 3.1 \mathrm{eV}\end{array}$ & $\begin{array}{c}\text { Indigo } 450 \mathrm{~nm} \\
2.76 \mathrm{eV}\end{array}$ & $\begin{array}{c}\text { Blue } 500 \mathrm{~nm} \\
2.48 \mathrm{eV}\end{array}$ & $\begin{array}{c}\text { Green } 550 \mathrm{~nm} \\
2.25 \mathrm{eV}\end{array}$ & $\begin{array}{c}n \text { Yellow 600nn } \\
2.07 \mathrm{eV}\end{array}$ & $\begin{array}{c}n \text { Orange } 650 \mathrm{~nm} \\
1.91 \mathrm{eV}\end{array}$ & $\begin{array}{c}\text { Red } 700 \mathrm{~nm} \\
1.77 \mathrm{eV}\end{array}$ & $C V$ \\
\hline B & 12536 & 13137 & 14497 & 15582 & 17054 & 19079 & 22598 & 27563 & 22 \\
\hline $\mathrm{Ca}$ & 40 & 33 & 19 & 12 & 16 & 13 & 28 & 49 & 43 \\
\hline $\mathrm{Mg}$ & 32 & 30 & 13 & 13 & 13 & 11 & 15 & 15 & 37 \\
\hline $\mathrm{Rb}$ & 108 & 103 & 74 & 76 & 81 & 79 & 79 & 76 & 12 \\
\hline
\end{tabular}

$\mathrm{El}=$ element



Figure2: Distribution profile of boron leeching from the plastic bottle into the water after exposure to specific photon energy of visible spectrum of light

The $\mathrm{pH}$ of different E-waters was determined and found to be about 5.5. The addition of sodium bicarbonate to water changes the solubility profile. The solubility showed a variable pattern where the sodium bicarbonate solubility of E-control was between E-green and E-blue. Interestingly, E-indigo exhibited maximal solubility while E-orange exhibited greatest insolubility (Figure 3).

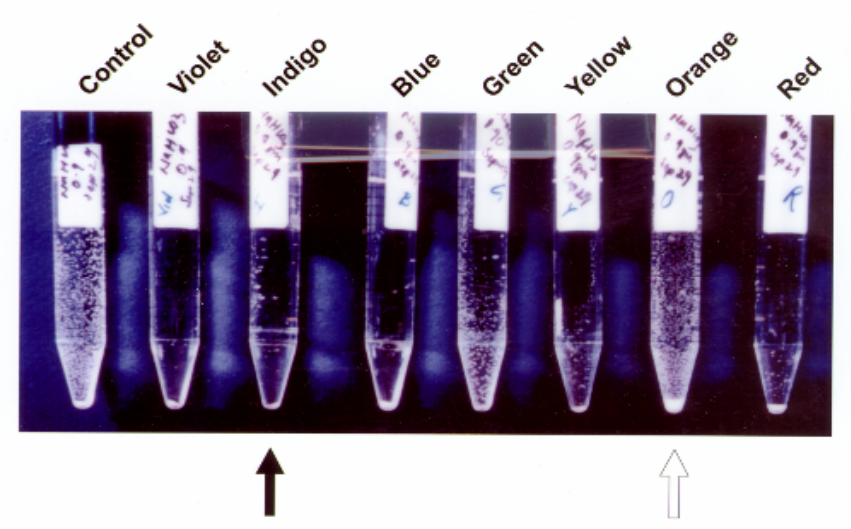

Figure 3: Each tube contains 1.0 gram of sodium bicarbonate with different E-water. Macroscopic evaluation exhibits maximum solubility with E-I and maximal insolubility with E-O. 
Physical conductance of each E-water as measured, using a Wheatstone Bridge type conductivity meter, was found to be five-fold higher in E-Indigo than in E-control $(p<0.01$; Figure 4$)$.

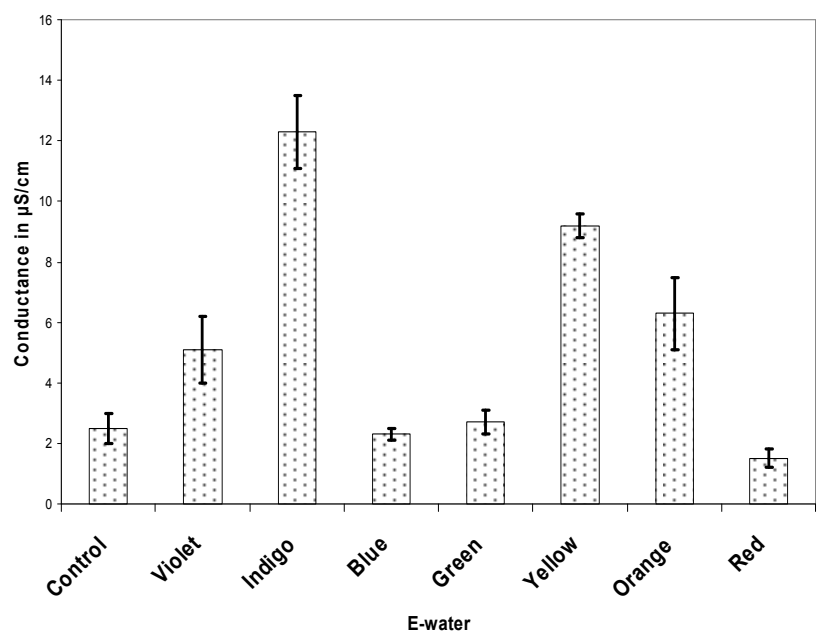

Figure 4: The Conductivity of different E-waters using conductance meter (Wheatstone Bridge). Measurements were taken in triplicate and are represented as Mean \pm SD.

A gradual increase in osmolarity between E-Violet and E-Yellow; and between E-Orange and E-Red was noted (Figure 5A). However, E-Yellow, E-Orange and

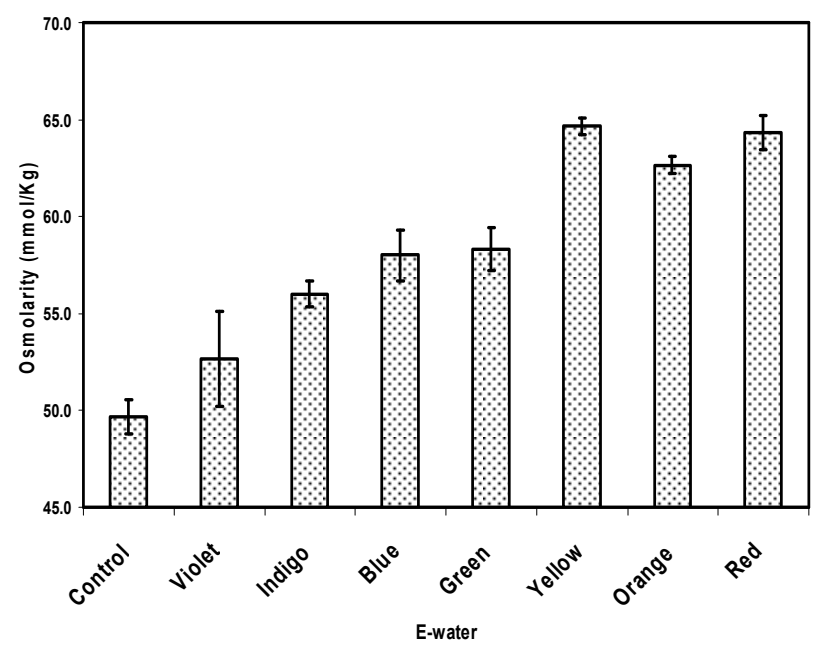

Figure 5A: Osmolarity study of different E-waters by Osmometer. Measurements were taken in triplicate and are represented as Mean $\pm \mathrm{SD}$.

E-Red waters exhibited higher osmolarity when compared with E-control. The binomial equation for the distribution of osmolarity which gives the best fit is:

$y=0.0054 x^{2}-0.7335 x+26.931$, with an

$\mathrm{R}^{2}=0.9325$, where

$\mathrm{y}=$ photon energy in electron volts $(\mathrm{eV})$, and

$\mathrm{x}$ is the osmolarity (mmol/Kg) (Figure $5 \mathrm{~B}$ ).

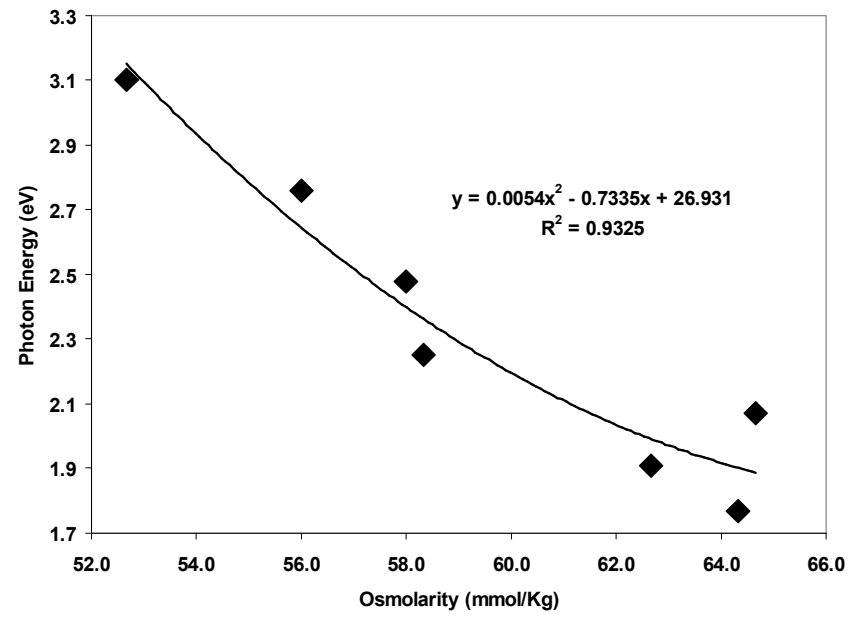

Figure 5B: Mathematical Relationship between photon energy and osmolarity of different E-waters

Second, the effect of E-water on $\mathrm{T}$ cell proliferation was assessed. $T$ cells in media alone and in the presence of $\mathrm{P}$, are considered as base value (Figure 6). While most E-water tests showed some degree of suppression of T-cell proliferation, E-blue showed complete inhibition of PHA stimulated $\mathrm{T}$ cell proliferation. The viability of cells was $\geq 90 \%$ in all conditions as measured by trypan blue, suggesting that the inhibition in proliferation was not due to some toxic reagent.

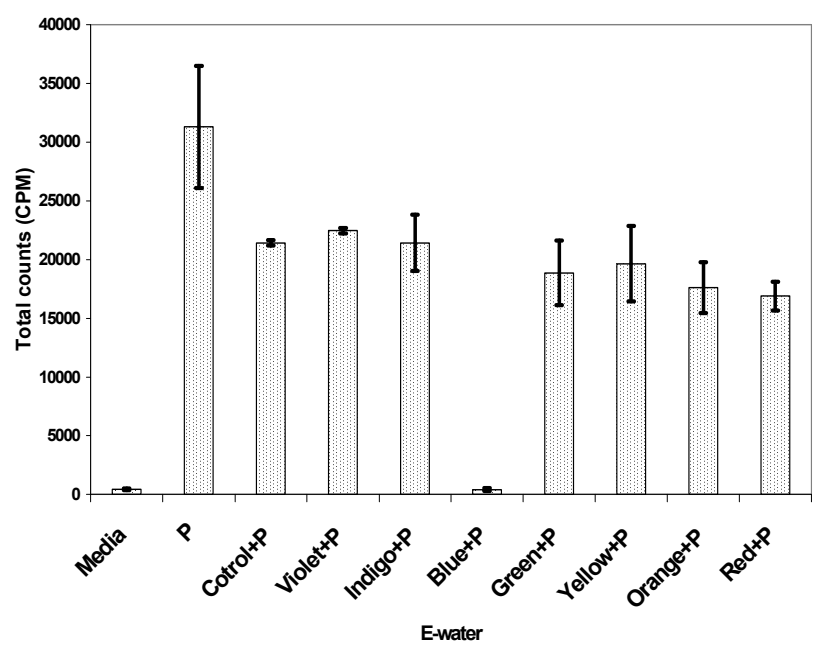

Figure 6: The proliferative responsiveness of peripheral blood $\mathrm{T}$ cells with different irradiated waters to phytoheamagglutinin (P). Cells were incubated with media, media $+\mathrm{P}$ and with media $+\mathrm{P}+\mathrm{E}$ water passed through $0.22 \mu$ filter. The experiments were done thrice in triplicates and are represented as Mean $\pm \mathrm{SD}$.

Third, the impact of the irradiated water on the growth of mosquito larvae was assessed. Data shown in Table 2 are observations from $\mathrm{t}=24 \mathrm{hrs}, 48 \mathrm{hrs}, 72 \mathrm{hrs}, 96$ hrs. The experiment was carried out for 10 days ( 240 hrs), however, no difference was noted between 96 and $240 \mathrm{hrs}$ (data not shown). These studies indicate that Eviolet and E-indigo showed similar values to E-control 
Table 2: Mean \pm S.D. of $\%$ mosquito larvae survival in differing concentrations of $E$-waters at $\mathrm{t}=24,48,72$ and 96 hours

\begin{tabular}{lccccccrr}
\hline & Control & Violet & Indigo & Blue & Green & Yellow & Orange & Red \\
\hline Undiluted & $33 \pm 21$ & $33 \pm 21$ & $33 \pm 19$ & $0 \pm 0$ & $0 \pm 0$ & $100 \pm 00$ & $97 \pm 5$ & $100 \pm 0$ \\
$1: 10$ & $33 \pm 21$ & $33 \pm 21$ & $13 \pm 8$ & $0 \pm 0$ & $0 \pm 0$ & $100 \pm 0$ & $93 \pm 10$ & $47 \pm 10$ \\
$1: 100$ & $33 \pm 21$ & $12 \pm 6$ & $13 \pm 8$ & $0 \pm 0$ & $0 \pm 0$ & $37 \pm 29$ & $90 \pm 16$ & $0 \pm 0$ \\
\hline
\end{tabular}

$\mathrm{t}=24 \mathrm{hrs}$

\begin{tabular}{lccccccrr}
\hline & Control & Violet & Indigo & Blue & Green & Yellow & Orange & Red \\
\hline Undiluted & $33 \pm 24$ & $33 \pm 24$ & $30 \pm 21$ & $0 \pm 0$ & $0 \pm 0$ & $100 \pm 00$ & $97 \pm 2$ & $100 \pm 00$ \\
$1: 10$ & $33 \pm 24$ & $33 \pm 24$ & $13 \pm 9$ & $0 \pm 0$ & $0 \pm 0$ & $100 \pm 00$ & $97 \pm 2$ & $50 \pm 10$ \\
$1: 100$ & $33 \pm 24$ & $10 \pm 7$ & $13 \pm 9$ & $0 \pm 0$ & $0 \pm 0$ & $67 \pm 12$ & $93 \pm 5$ & $0 \pm 0$ \\
\hline
\end{tabular}

$\mathrm{t}=48 \mathrm{hrs}$

\begin{tabular}{lccccccrr}
\hline & Plain & Violet & Indigo & Blue & Green & Yellow & Orange & Red \\
\hline Undiluted & $33 \pm 24$ & $33 \pm 24$ & $30 \pm 21$ & $0 \pm 0$ & $7 \pm 5$ & $100 \pm 00$ & $97 \pm 2$ & $100 \pm 00$ \\
$1: 10$ & $33 \pm 24$ & $33 \pm 24$ & $13 \pm 9$ & $0 \pm 0$ & $0 \pm 0$ & $100 \pm 00$ & $97 \pm 2$ & $53 \pm 2$ \\
$1: 100$ & $33 \pm 24$ & $10 \pm 7$ & $27 \pm 19$ & $0 \pm 0$ & $0 \pm 0$ & $67 \pm 2$ & $93 \pm 5$ & $33 \pm 24$ \\
\hline
\end{tabular}

$\mathrm{t}=72 \mathrm{hrs}$

\begin{tabular}{lccccccrr}
\hline & Control & Violet & Indigo & Blue & Green & Yellow & Orange & Red \\
\hline Undiluted & $33 \pm 24$ & $33 \pm 24$ & $30 \pm 21$ & $0 \pm 0$ & $30 \pm 21$ & $100 \pm 00$ & $97 \pm 2$ & $100 \pm 00$ \\
$1: 10$ & $33 \pm 24$ & $33 \pm 24$ & $27 \pm 19$ & $0 \pm 0$ & $30 \pm 21$ & $100 \pm 00$ & $97 \pm 2$ & $73 \pm 9$ \\
$1: 100$ & $33 \pm 24$ & $13 \pm 9$ & $30 \pm 21$ & $0 \pm 0$ & $87 \pm 5$ & $73 \pm 9$ & $97 \pm 2$ & $33 \pm 23$ \\
\hline
\end{tabular}

$\mathrm{t}=96 \mathrm{hrs}$

Table 3: Mean \pm SD in millimeters of the growth of cotyledons of gram beans following incubation with $E$-waters at $t=48$ and 72 hrs. Mean of E-control is compared to other E-waters for enhanced growth by multiple comparison procedure (Turkey test). Three types of water tested were viz; Distilled-water in plastic bottles (DWPB), Well-water in glass bottle (WWGB) and Distilled-water in glass bottle (DWGB).

\begin{tabular}{|c|c|c|c|c|c|c|c|c|}
\hline & Control & Violet & Indigo & Blue & Green & Yellow & Orange & Red \\
\hline \multirow[t]{2}{*}{ DWPB } & $0.78 \pm 0.10$ & $1.32 \pm 0.21$ & $1.54 \pm 0.18$ & $1.38 \pm 0.22$ & $0.90 \pm 0.15$ & $1.94 \pm 0.20$ & $2.51 \pm 0.29$ & $0.17 \pm 0.05$ \\
\hline & NS & $\mathrm{p}<0.05$ & $\mathrm{p}<0.05$ & $\mathrm{p}<0.05$ & $\mathrm{P}<0.05$ & $\mathrm{p}<0.05$ & $p<0.05$ & \\
\hline \multirow[t]{2}{*}{ WWGB } & $8.0 \pm 2.1$ & $4.5 \pm 1.2$ & $7.2 \pm 1.9$ & $0.2 \pm 0.2$ & $1.6 \pm 0.60$ & $4.0 \pm 1.50$ & $8.0 \pm 2.5$ & $0.9 \pm 0.6$ \\
\hline & & & NS & & & & NS & \\
\hline \multirow[t]{2}{*}{ DWGB } & $0.1 \pm 0.0$ & $5.6 \pm 1.2$ & $4.4 \pm 1.8$ & $0.9 \pm 0.6$ & $1.8 \pm 1.20$ & $3.9 \pm 2.3$ & $5.7 \pm 1.8$ & $0.2 \pm 0.2$ \\
\hline & & $p<0.05$ & $p<0.05$ & NS & $p<0.05$ & $p<0.05$ & $p<0.05$ & NS \\
\hline \multicolumn{9}{|l|}{$\mathrm{t}=48 \mathrm{hrs}$} \\
\hline & Control & Violet & Indigo & Blue & Green & Yellow & Orange & Red \\
\hline \multirow[t]{2}{*}{ DWPB } & $2.4 \pm 0.3$ & $3.8 \pm 0.4$ & $3.6 \pm 0.4$ & $3.1 \pm 0.5$ & $2.7 \pm 0.3$ & $5.2 \pm 0.5$ & $7.1 \pm 0.7$ & $0.6 \pm 0.01$ \\
\hline & & $\mathrm{p}<0.05$ & $\mathrm{p}<0.05$ & $\mathrm{p}<0.05$ & $\mathrm{P}<0.05$ & $\mathrm{p}<0.05$ & $\mathrm{p}<0.01$ & \\
\hline \multirow[t]{2}{*}{ WWGB } & $20.9 \pm 3.2$ & $23.1 \pm 3.5$ & $26.0 \pm 4.9$ & $10.7 \pm 2.1$ & $2.9 \pm 1.1$ & $32.6 \pm 6.2$ & $45.8 \pm 4.7$ & $4.3 \pm 1.7$ \\
\hline & & NS & $\mathrm{p}<0.05$ & & & $\mathrm{p}<0.05$ & $\mathrm{p}<0.05$ & \\
\hline \multirow[t]{2}{*}{ DWGB } & $6.1 \pm 1.0$ & $23.5 \pm 4.1$ & $25.0 \pm 5.4$ & $2.8 \pm 1.1$ & $6.6 \pm 6.7$ & $16.6 \pm 4.8$ & $34.3 \pm 1.5$ & $1.4 \pm 0.6$ \\
\hline & & $p<0.001$ & $p<0.001$ & & NS & $p<0.05$ & $p<0.001$ & \\
\hline
\end{tabular}

$\mathrm{t}=72 \mathrm{hr}$ 
for viability when tested undiluted, while E-blue and Egreen greatly inhibit larval growth for up to 72 hours. Eyellow, E-orange and E-red promoted the hatching of mosquito larvae, except E-red in dilutions of 1:10 and 1:100. E-control showed only $1 / 3$ hatching compared to E-green after 96 hours (Table 2). E-blue completely abolished larvae growth in the three concentrations tested (undiluted, 1:10, 1:100).

Finally, the effect of E-water on seed germination was investigated (Table 3). After 48 hours of incubation, the seeds in the DWPB showed significant enhanced growth $(p<0.05)$ with E-indigo, E-yellow, and E-orange, while seeds in the DWGB showed enhanced growth with all colors when compared to E-control. WWGB showed growth in E-violet, E-indigo, E-green, E-yellow and Eorange after 48 hours but not in E-blue or in E-red. In contrast, after 72 hours, the seeds in the DWPB showed the most significantly enhanced growth with the Eyellow and E-orange water ( $\mathrm{p}<0.05,<0.01$ respectively). The WWGB showed enhanced growth with E-yellow and E-orange and the DWGB showed enhanced growth with E-violet, E-indigo, E-yellow $(p<0.05)$ and E-orange $(p<0.001)$. E-red water suppressed seed germination at 72 hours in all the three water groups tested.

\section{Discussion}

Plastic vessels allow only $50 \%$ transmission of light while glass vessels allow about $90 \%$ transmission. This means that there is more solar energy delivered in glass versus plastic. In germination experiments we demonstrated that maximal root elongation and minimal root elongation were independent of the vessel i.e., plastic vs glass but were dependent on the wavelength of light rather than intensity. Thus, implying that the energy transfer is dependent on the wavelength rather than the amount of sunlight the vessel receives. Also the effect of organic material like plasticisers for example dibutyl pthalate and other esters used in the synthesis of plastic bottles is not known. Whether the variation of conductance, osmolarity, salt-solubility and chemical composition of the different types of water had any impact on the germination process, mosquito larva survival, or cell proliferation requires further investigation. Likewise, the influence of lunar irradiation, if any cannot be ascertained. Classically, electronic transition like $n \rightarrow n, \pi \rightarrow \pi^{*}$ and $n \rightarrow \pi$ occur in the ultraviolet region which can lead to photolytic effect of water but the outcome of these transitions in the visible spectrum is unknown. It is possible that the photochemical effect observed could have been a thermal effect based on solar spectral irradiance ([2]. This postulate cannot be authenticated because the temperature of the E-waters in the bottles was not recorded during the experiment. The conductivity, mosquito hatching, T cell-data, some ICP data and the osmolarity data seem to mimic the solar energy spectrum with a maximum effect in the blue-green region. Furthermore, the E-waters were tested at least three months after being at room temperature where the thermal effect if any, would have been equilibrated.
Since boron is constantly increased in concentration from violet to red, the change in elemental concentration could possibly be due to the overall excess heating by red cellophane paper, which allows more leaching. It is not known whether the leached elements were present due to the process of the manufacture of the polypropylene-polyethylene plastic. On the other hand, we know that the distilled water was handled in the same manner for all test-bottles. Since the elemental composition is different after 40-day exposure at certain wavelengths of sunlight, there is an implication that there is a solar effect causing leaching of some components contained in the plastic. Further investigation is on going to determine the source of boron and other elemental composition after irradiation. Swiss studies, however, have shown that photoproducts are formed after solar exposure on the outer surface of the plastic bottle and that no substances hazardous to the health are leached into the water through the bottle [4]. In contrast to the Swiss study, in our study we report leaching of elements into the water [3].

The exposure of water to sunlight has no influence on the $\mathrm{pH}$ of water. It has been reported that a solution of sodium bicarbonate in 10 parts of water is soluble at $25^{\circ} \mathrm{C}$ with a resulting $\mathrm{pH}$ of 8.3 when freshly prepared [13]. Thus, using sodium bicarbonate solubility as an example at room temperature, we are at the edge of solubility in which the solute must be fairly soluble. Whether the greater insolubility of the E-orange water as compared to E-control was due to density clouds of water molecules increasing the forces of repulsion, or whether the forces of attraction of the sodium bicarbonate were reduced is not known. Attractive forces in the molecular structure of sodium bicarbonate may have undergone changes in order to sediment rather than solubilize as observed with E-orange. The ion-dipole interactions seem to be predominant in terms of increasing $\Delta \mathrm{H}$ of solubility. In other words there is maximal enthalpy of solution $(\Delta \mathrm{H})$ for E-indigo while Eorange has minimal enthalpy of solution in our study. This is a clear-cut indication that exposure to specific solar spectrum energizes the water resulting a change in the pattern of salt solubility.

Leached chemicals such as boron, calcium, magnesium and rubidium appear in such minute quantities (ppb) as would not cause difference in conductance. Thus, the increased conductance such that we observed with E-indigo must be due to some modification by the irradiation process. Because there is no significant contribution of the concentration of elements, it is reasonable to assume a constant current, implying that the voltage generated by the red cellophane-wrapped bottled water would be greater than the voltage generated by the indigo cellophane-wrapped bottled water (voltage $\mathrm{x}$ conductance $=$ current). Thus, the differences in voltages would cause a potential difference, meaning that energy is trapped in the water and manifesting as a potential difference. It is very unlikely that the difference in conductance is due to the impurities that create differences in ionic composition due to the use of distilled water which is devoid of 
contamination. It is noteworthy to mention that in a separate study; only E-yellow reacted with prostate related substance in the urine of cohort of patients with a serum prostate specific antigen in the range of 0.21-4.0 $\mathrm{ng} / \mathrm{ml}[14]$.

Elements present in the water contribute to the osmolarity of E-water. The added total of all elements in the system such as the leached chemicals contribute minimally. Considering boron by itself, concentration ranges from $1.16 \mathrm{mM}$ baseline (control) to $2.55 \mathrm{mM}$ in E-red while the sums of the other elements are in the nanomolar range. Such low concentration of the leached chemicals as measured in these waters would not account for this difference in osmolarity, which was found after the irradiation. Thus, the alteration in osmolarity that we observed is related to some unique phenomenon which is not defined by the elemental composition of the tested waters.

Healing is associated with the immune system. In disease eruptions, suppression of an immune response via the $T$ cell network, is of utmost importance in various instances as in transplant immunology and autoimmune diseases. Data on $\mathrm{T}$ cell proliferation demonstrated that E-blue showed maximal inhibition of PHA stimulated $\mathrm{T}$ cell proliferation by a non toxic mechanism. The immunosuppression of $\mathrm{T}$ cells lends credibility to the possibility of a particular E-water to be of importance in a disease paradigm.

Solar energy has been used to detoxify water infected with viral and bacterial contamination [2-5]. However, solarized water has not been used to address the problem of mosquito biology. Since mosquitoes can spread disease the issue of mosquito control is of great importance. All mosquitoes spend their larval and pupal stages in water and our study has used this observation to study mosquito viability. These studies indicate that Eviolet and E-indigo showed similar values to E-control for viability when tested undiluted, while E-blue and Egreen greatly inhibit larval growth for up to 72 hours. Eyellow, E-orange and E-red promoted the hatching of mosquito larvae, except E-red in dilutions of 1:10 and 1:100. E-control showed only $1 / 3$ hatching compared to E-green after 96 hours (Table 2). The most interesting finding was that E-blue completely abolished larvae growth in the three concentrations tested (undiluted, $1: 10,1: 100)$. The abolishment of mosquito larva in Eblue water at different dilutions provides evidence to the possibility of spraying stagnant waters with the E-blue water to destroy mosquitoes.

Water is the most abundant ingredient of active plant cells [10]. Seed germination does not require sunlight or soil, but it requires water [10]. Germination aids in the hydrolysis of the complex into simple sugars that are readily utilized in the synthesis of auxins and proteins [15]. The auxins help to soften cell walls to facilitate growth and the proteins are readily utilized in the production of new plant tissues [15]. Thus, germination when accelerated is capable of improving crop yield and boasting farmers income in agricultural industry involved in growing crops such as tomatoes (Lycopersecum esculentum Mill) and tamarind
(Tamarindus indica L) $[15,16]$ Our germination studies showed that regardless of the vessel at 72 hours, Eorange enhanced while E-red inhibited seed germination when compared to E-control. Results indicate that a change took place independent of the source of water (well water versus double distilled), type of container (plastic or glass), or the season of the year (summer versus fall). Distilled water when compared to well water has a reduced load of microorganisms. The change in photochemical property of well water in comparison to distilled water maybe due to the presence of microorganisms in the well water. The mode of energy transfer however, as these investigations indicate, seems to be governed by a process independent of the presence of bacterial and viral contaminants. In both well and double distilled water at 72 hours with E-orange there was a maximal activation of seed germination. Thus, change in the pattern of seed germination by E-water appears to be solely dependent on the wavelength of sunlight rather than the type or source of water used. Eorange showed enhanced growth both in plastic containers and glass containers

\section{Conclusion}

In conclusion, in this paper we have shown that:1) exposure of water to specific solar spectrum for a period of 40 days alter a) boron concentration, b) $\Delta \mathrm{H}$ of solubilization with sodium bicarbonate, c) E-indigo induced five-fold greater conductivity in the water when compared to the effect of E-red, d) osmolarity, e) T cell proliferation by total suppression of mitogen stimulated T cell proliferation by E-blue, f) mosquito larva hatching abolished by E-blue but not other E-waters, and g) germination with E-orange giving the maximal elongation of bean roots. Additionally, our results (Figure 5A and $\mathrm{B}$ ) suggest for a unique phenomenon of osmolarity change without involvement of the concentration of the solutes present in the water. This is the first study to show that the penetration of sunlight through specific colored cellophane wrapped bottles changes chemical, physical and biological properties of water.



Figure 7: Maximum changes in properties of water as specific wavelength range. 
The results of these changes are summarized in Figure 7. There is strong indication that 40-day incubation in sunlight results in storing solar energy as potential energy, which can be utilized as kinetic energy in various biological systems. These results are novel and open new possibilities for the investigation and understanding of the role of exposed water through different colors of the solar spectrum for plant, insects and human life.

Acknowledgements: We thank Dr. Manoj Shukla, Dr. Ramaiyer Venkatraman, Dr. Johanne Bauer, Dr. Ingrid Glurich, Dr. Cindy Cohly and Taylor Schwalenberg for their valuable criticisms in the preparation of the manuscript, and Dr. A. K. Markov for helpful discussions.

\section{References}

1. Rothschild, L. J., Mancinelli, R. L. Life in extreme environments. Nature 2001, 409, 1092-1101. www.idrc.ca/library/document/041882/041882b.htm 1 visited 9-5-04.

2. Wegelin, M.; Canonica, S.; Alder, A. C.; Marazuela, D.; Suter, M. J.-F.; Bucheli, Th. D.; Haefliger, O. P.; Zenobi, R.; McGuigan, K. G.; Kelly, M.; TIbrahim, P.; Larroque, M.: Does sunlight change the material and content of polyethylene terephthalate (PET) bottles?, IWA Publishing, Journal of Water Supply: Research and Technology - Aqua, 2001, 50, No.

3. Accra, A.; Jurdi, M.; Mu'allem, H.; Karahagopian, Y.; Raffoul, Z.: Water Disinfection by Solar Radiation: Assessment and Application. International Development Research Center IDRCTS66e, Ottawa, Ontario, Canada, 1990.

4. McGuigan, K. G. ; Joyce, T. M. ; Conroy, R. M.: Solar disinfection using sunlight to decontaminate drinking water in developing countries. J. Med. Microbiol. 1999, 48, 758-787.

5. Chellemi, D. O.; Olson, S. M.; Mitchell, D. J.; Secker, I.; McSorley, R.: Adaptation of soil solarization to the integrated management of soilborne pests of tomato under humid conditions. Phytopathology 1997, 87, 250-258.

6. Willard, J. W.: Method of therapeutically treating damaged and/or infected tissue in warm blooded animals and compositions therefore, US patent 3,984,540, October 5. 1976.

7. Bickers, D. R.; Pathak, M. A.: Psoralen pharmacology: studies on metabolism and enzyme induction. National Cancer Institute Monographs, 1984, 66, 77-84.

8. Obenhuber, D. C.; McCaleb R. C.: Microtox Toxicity Test compared with the Daphnid, Flathead Minnow Acute Lethality Tests. Proceedings of the Aerospace Environmental Technology Conference 1998, (2), 700.

9. Cohly, H. H. P. ; Morrison D. R. ; Atassi, M. Z.: Conformation Dependent Recognition of a Protein by T Lymphocytes: Apomyoglobin Specific T Cell Clone Recognizes Conformational Changes Between Apomyoglobin and Myoglobin. Immunol. Invest. 1988, 17, 337-342.

10. Lorenz, K.: Cereal Sprouts: Composition, nutritive value, food applications. CRC Handbook of Tropical Food Crops, Editor Franklin W. Martin, Critical Reviews in Food Science and Nutrition 1980, 353-385.

11. ASTM G159-98 Standard Tables for References Solar Spectral Irradiance at Air Mass 1.5, Copyright American Society for Testing and Materials, West Conshohocken, PA. All rights reserved. http://www.astm.org/cgibin/SoftCart.exe/DATABASE.CART/PAGES/G159 htm?L+myst. 2001.

12. Faith, Keyes \& Clark's: Industrial Chemicals, Lowenheim, F. A. and M. K.; Moran, M. K., eds. Wiley-Interscience: New York, $4^{\text {th }}$ ed., 1975, pp. 702-705.

13. Cohly H. H. P.; Koelle, M. S.; Angel, M. F.; Das, S. K.; Shingleton, W. B.: Pilot Study: A Non-Invasive Urine Test for Potential Prostate Abnormalities. Int. J. Mol. Sci. 2002, 3, 1039-1047.

14. Sabongari, S.; Aliero, B. L.: Effects of soaking duration on germination and seedling growth of tomato (Lycopersicum esculentum Mill) African Journal of Biotechnology 2004, 3, 47-51.

15. Muhammad, S.; Amusa, N. A.:. Effects of sulphuric acid and hot water treatments on seed germination of tamarind (Tamarindus indica L). African Journal of Biotechnology, 2003, 2, 276-279. 